\title{
PENGARUH KUALITAS PRODUK DAN HARGA TERHADAP KEPUTUSAN \\ PEMBELIAN TUPPERWARE PADA DISTRIBUTOR ISHWARYA PARAMA CIPUTAT TIMUR TANGERANG SELATAN
}

\author{
${ }^{1}$ Nur Hikmah Dwi Ningrum, ${ }^{2 *}$ Ali Maddinsyah \\ Universitas Pamulang, Tangerang, Banten, Indonesia \\ *alimaddinsyah@unpam.ac.id
}

\begin{abstract}
Abstrak
Penelitian ini bertujuan untuk mengetahui pengaruh kualitas produk terhadap keputusan pembelian Tupperware, mengetahui pengaruh harga terhadap keputusan pembelian Tupperware dan mengetahui pengaruh kualitas produk dan harga terhadap keputusan pembelian Tupperware. Metode yang digunakan adalah deskriptif dengan pendekatan asosiatif. Sampling yang digunakan probability sampling dengan rumus Slovin, sedangkan untuk mendapatkan data dilakukan dengan menyebar kuesioner kepada 98 responden yang kemudian dianalisis pengaruh secara parsial dan simultan dengan menggunakan analisis regresi, koefisien determinasi serta pengujian hipotesis dengan uji t dan uji F. Hasil penelitian menunjukkan bahwa : pengaruh kualitas produk terhadap keputusan pembelian sebesar $46,5 \%$, pengaruh ini positif dan signifikan.
\end{abstract}

Kata Kunci: Kualitas Produk, Harga dan Keputusan Pembelian

\section{Abstract}

This research aims to determine the effect of product quality on Tupperware purchasing decision, determine the effect of price on Tupperware purchase decions and determine the effect of product quality and price on Tupperware purchase decions. The method used is descriptive with an associative approach. Sampling used probability sampling with the Slovin formula, while to get data done by distributing questionnaires to 98 respondents who then analyzed the influence partially and simultaneously using regression analysi, coefficient of detetermination and hypothesis testing with $t$ test $f$ test. The results showed that : the effect of product quality on purchasing decisions of $46,5 \%$, this effect is positive and significant.

Keywords: Product Quality, Price and Purchase Decisions

\section{PENDAHULUAN}

Tupperware adalah perusahaan multinasional yang memproduksi dan memasarkan produk plastik berkualitas untuk rumah tangga.Kantor pusatnya berkedudukan di Orland Amerika Serikat. Dengan sistem penjualan Direct Selling (Penjualan Langsung). Kini Tupperware berkembang sangat pesat dan menjangkau pasar lebih dari 100 Negara. Di banyak Negara, Tupperware selalu menempati ranking atas di antara perusahaanperusahaan Direct Selling lainnya.

Tupperware mulai dikenal masyarakat Indonesia sekitar tahun 1978. Namun, nyatanya belum dapat berkembang luas, karena belum memiliki kantor perwakilan dan distributor resmi
Tupperware di Indonesia. Pada tanggal 11 Juni 1991 diadakanlah pesta Tupperware pertama di Jakarta. Inilah cikal bakal bisnis Tupperware yang begitu hebat di Indonesia. Dapat dikatakan pada tahun 1991-1994 merupakan masa peletakan pondasi bagi Tupperware Indonesia, tahun 1995 perlahan-lahan Tupperware bangkit dan berkembang pesat pada periode berikutnya.

Produk Tupperware terbuat dari bahan plastik berkualitas terbaik. Produk plastik yang berkualitas tinggi, higienis, aman dan sehat serta kedap udara, tidak mengandung zat kimia beracun dan sudah memenuhi standart dari beberapa badan dunia seperti FDA (Food and Drug Administration) Amerika, European Food 
Safety Authority (Eropa), Japan Food Safety Commision (Jepang), sehingga selain aman digunakan berkali-kali untuk makanan dan minuman (Food Grade) juga ramah lingkungan, higienis serta eco design karena produk Tupperware yang rusak bisa di daur ulang menjadi produk lain seperti bangku plastik, pot tanaman, tempat sampah dan lain-lain.

Produk Tupperware yang secara konsisten menjaga kualitas produknya agar konsumen yang membeli merasa puas setelah menggunakan produk tersebut. Salah satu cara produk Tupperware dalam menjaga kualitas terhadap produk Tupperware adalah dengan uji layak pakai setiap produknya sebelum dipasarkan, hal ini dilakukan agar produk dapat bersaing dipasaran dan memiliki citra yang baik bagi konsumen.

Selain kualitas produk, harga juga diduga dapat mempengaruhi keputusan pembelian.Setiap perusahaan selalu mengejar keuntungan guna kesinambungan produksi.Keuntungan yang diperoleh ditentukan pada penetapan harga yang ditawarkan.Harga suatu produk ditentukan dari pengorbanan yang dilakukan untuk menghasilkan jasa dan laba atau keuntungan yang diharapkan.Oleh karena itu, penentuan harga produk dari suatu perusahaan merupakan masalah yang cukup penting.

\section{TINJAUAN PUSTAKA}

1. Kualitas Produk

Kualitas produk adalah suatu kondisi fisik, sifat, dan fungsi produk, baik itu produk barang atau produk layanan jasa, berdasarkan tingkat mutu yang disesuaikan dengan durabilitas, reliabilitas, serta mudahnya penggunaan, kesesuaian, perbaikan serta komponen lainnya yang dibuat untuk memenuhi kepuasan dan juga kebutuhan pelanggan.

Prawirosentono menjelaskan bahwa kualitas produk adalah suatu ciri khas tertentu dari produk yang mampu memenuhi ekspektasi konsumen.

Dimensi Kualitas Produk a. Kinerja

Tingkat penilaian kinerja adalah suatu penilaian terkait bagaimana suatu produk bisa disajikan dan juga ditampilkan pada pelanggan. Tingkat penilaiannya akan fokus pada karakteristik dasar dari produk tersebut, contohnya adalah dimensi kinerja dari produk makanan adalah rasa dari makanan itu sendiri.

b. Keandalan

Tingkat keandalan dan juga konsistensi dari suatu produk dalam proses pengerjaan maupun pembuatannya sangat mempengaruhi minat konsumen. Keandalan sangat erat kaitannya dengan minat pelanggan dan bagaimana mendapatkan kepercayaan dari pelanggan.

c. Keistimewaan

Karakteristik sekunder ini hadir sebagai pelengkap dan bisa diartikan sebagai kelengkapan atas berbagai atribut produk yang tersedia pada suatu produk. Di beberapa waktu tertentu, kinerja pada suatu produk akan sesuai dengan pesaingnya, namun yang membedakan adalah fitur yang terkandung di dalamnya.

d. Kesesuaian

Ciri khas yang berkaitan dengan desain pada suatu produk akan menghasilkan kesesuaian standar yang sebelumnya sudah ditentukan berdasarkan kesepakatan yang ada sebelumnya.

e. Daya Tahan

Daya tahan produk adalah karakteristik yang erat kaitannya dengan berapa lama tingkat ketahanan produk tersebut. Pada produk makanan atau minuman, biasanya akan diartikan dengan tanggal kadaluarsa.

f. Kemampuan Melayani

Dalam hal ini, kemampuan dalam hal melayani berhubungan langsung dengan tingkat kecepatan, kompetensi, dan juga kenyamanan yang bisa diberikan oleh suatu 
perusahaan kepada pelanggannya yang terkait dengan penanganan jika nantinya ada keluhan pada produk yang diproduksi oleh perusahaan.

g. Estetika

Estetika adalah suatu keindahan pada suatu produk yang berhubungan dengan panca indera, dimana produk tersebut mampu menggambarkan nilai keindahan yang erat kaitannya dengan rasa, desain, aroma

2. Harga Produk

Menurut Peter dan Olson (2000) harga didefinisikan jumlah uang yang harus diserahkan konsumen untuk membeli suatu produk atau jasa. Harga merupakan satu-satunya elemen yang berkaitan dengan pendapatan. Menurut Kotler dan Amstrong (2008) harga adalah sejumlah uang yang dibebankan atas produk atau jasa atau jumlah dari nilai yang ditukar konsumen atas manfaat-manfaat karena memiliki atau mengunakan produk atau jasa tersebut.

Harga menurut Willian J Stanton (1994) adalah jumlah uang yang dibutuhkan untuk mendapatkan sejumlah kombinasi dari barang beserta pelayanannya. Indikator yang mencirikan

harga menurut Willian J Stanton (1994) yaitu: (1). Keterjangkauan harga produk, (2). Harga yang sesuai dengan kualitas produk, (3). Harga yang sesuai dengan manfaat suatu produk, dan (4). Daya saing harga produk.

Kesan konsumen terhadap harga baik itu mahal, murah maupun standar akan berpengaruh aktivitas pembelian selanjutnya dan kepuasan konsumen setelah pembelian. Kesan ini akan menciptakan nilai persepsi konsumen terhadap suatu barang. Manakala konsumen kecewa setalah membeli suatu barang ternyata terlalu mahal menurut konsumen, maka kemungkinan selanjutnya dia akan enggan untuk membeli barang itu lagi dan bisa jadi beralih ke barang lain.
Strategi penetapan harga menurut Peter dan Olson (2000) ialah suatu perlu yang diperhatikan dalam tiga situasi berikut ini ketika harga suatu produk baru sedang ditetapkan, ketika sedang mempertimbangkan melakukan perubahan jangka panjang bagi suatu produk yang telah mapan, dan ketika sedang mempertimbangkan melakukan perubahan harga jangka pendek. Pemasar dapat mengubah harga untuk berbagai macam alasan yang diajukan, seperti meningkatkan biaya, perubahan harga produk pesaing, atau adanya perubahan pada saluran distribusi

3. Keputusan Pembelian

Keputusan pembelian merupakan pemikiran dimana individu mengevaluasi berbagai pilihan dan memutuskan pilihan pada suatu produk dari sekian banyak pilihan. Menurut Kotler \& Amstrong (2014), keputusan pembelian adalah tahap dalam proses pengambilan keputusan pembeli di mana konsumen benar-benar membeli.

Menurut Schiffman dan Kanuk (2014) keputusan pembelian didefinisikan sebagai sebuah pilihan dari dua tahu lebih alternatif pilihan. Menurut Tjiptono (2012) keputusan pembelian adalah sebuah proses dimana konsumen mengenal masalahnya, mencari informasi mengenai produk atau merek tertentu dan mengevaluasi secara baik masing-masing alternatif tersebut dapat memecahkan masalahnya, yang kemudian mengarah kepada keputusan pembelian.

Dari pengertian tersebut dapat disimpulkan keputusan pembelian merupakan sebuah proses pengambilan keputusan yang diawali dengan pengenalan masalah kemudian mengevaluasinya dan memutuskan produk yang paling sesuai dengan kebutuhan

\section{METODE}

Jenis penelitian ini adalah asosiatif, menurut Sugiyono (2017:44) yaitu "Penelitian yang bertujuan untuk 
mengetahui pengaruh atau hubungan antara dua variabel atau lebih".Dengan demikian penelitian asosiatif ini dapat dibangun suatu teori yang berfungsi untuk menjelaskan, meramalkan dan mengontrol suatu gejala.Penelitian ini bertujuan untuk menganalisa hubungan atau tingkat pengaruh variabel bebas (Kualitas produk dan Harga) terhadap variabel terikat (Keputusan pembelian).

Perusahaan yang menjadi tempat penelitian ini adalah Distributor Ishwarya Parama yang beralamat di Jalan Ir. H. Juanda Ruko Ciputat Indah Permai D.19 Ciputat Timur, Kota Tangerang Selatan. Waktu Penelitian ini dilaksanakan selama 3 (tiga) bulan yang dimulai dari Agustus Oktober 2020. Penelitian dilakukan secara bertahap diawali dengan penyusunan usulan skripsi, revisi usulan skripsi, pembuatan instrumen, pengumpulan data primer dan sekunder, penyebaran kuesioner, pengolahan data yang telah didapat oleh penulis dan penyusunan pelaporan hasil skripsi.

\section{HASIL DAN PEMBAHASAN}

Berdasarkan hasil penelitian yang didapatkan, maka dapat diungkapkan pembahasan pengaruh kualitas produk dan harga terhadap keputusan pembelian Tupperware pada Distributor Ishwarya Parama Ciputat Timur Tangerang Selatan, sebagai berikut:

1. Pengaruh Kualitas Produk terhadap Keputusan Pembelian Tupperware pada Distributor Ishwarya Parama Ciputat Timur Tangerang Selatan.

Berdasarkan hasil penelitian, menunjukkan bahwa kualitas produk (X1) berpengaruh positif terhadap keputusan pembelian (Y), berdasarkan hasil perhitungan regresi linear sederhana dapat diperoleh persamaan regresinya $Y=20,629+0,536 X 1$. Dapat diketahui bahwa pengaruh kualitas produk terhadap keputusan pembelian diperoleh nilai R2 sebesar 0,465 maka dapat disimpulkan bahwa variabel kualitas produk (X1) memberikan kontribusi sebesar $46,5 \%$ terhadap keputusan pembelian (Y) Tupperware pada Distributor Ishwarya Parama Ciputat Timur Tangerang Selatan. Berdasarkan nilai thitung $>$ ttabel $(9,244>$ 1,660 ), hal itu juga dibuktikan dengan signifikansi $0,000<0,05$. Dengan demikian maka $\mathrm{H} 1$ diterima, hal ini menunjukkan bahwa Kualitas Produk berpengaruh positif dan signifikan terhadap Keputusan Pembelian Tupperware pada Distributor Ishwarya Parama Ciputat Timur Tangerang Selatan.

2. Pengaruh Harga terhadap Keputusan Pembelian Tupperware pada Distributor Ishwarya Parama Ciputat Timur Tangerang Selatan.

Berdasarkan hasil penelitian, menunjukkan bahwa harga (X2) berpengaruh positif terhadap keputusan pembelian (Y), berdasarkan hasil perhitungan regresi linear sederhana dapat diperoleh persamaan regresinya $Y$ $=21,149+0,832 X 2$. Dapat diketahui bahwa pengaruh harga terhadap keputusan pembelian diperoleh nilai R2 sebesar 0,476 maka dapat disimpulkan bahwa variabel harga (X2) memberikan kontribusi sebesar $47,6 \%$ terhadap keputusan pembelian (Y) Tupperware pada Distributor Ishwarya Parama Ciputat Timur Tangerang Selatan. Berdasarkan nilai thitung $>$ ttabel $(9,441>$ 1,660), hal itu juga dibuktikan dengan signifikansi $0,000<0,05$. Dengan demikian maka $\mathrm{H} 2$ diterima, hal ini menunjukkan bahwa Harga berpengaruh positif dan signifikan terhadap Keputusan Pembelian Tupperware pada Distributor Ishwarya Parama Ciputat Timur Tangerang Selatan.

\section{KESIMPULAN}

Kualitas produk berpengaruh positif dan signifikan terhadap keputusan pembelian Tupperware pada Distributor Ishwarya Parama Ciputat Timur Tangerang Selatan. Hal ini dapat dilihat dari Nilai $t_{\text {hitung }}>t_{\text {tabel }}(9,244>1,660)$ dan signifikansi $t$ $<0,05(0,000<0,05)$ kualitas produk 
mempunyai korelasi positif dengan keputusan pembelian sebesar 0,536. Kualitas produk mempunyai kontribusi (R2) sebesar 46,5\% terhadap keputusan pembelian Tupperware pada Distributor Ishwarya Parama Ciputat Timur Tangerang Selatan. Model regresi sederhana yang diperoleh adalah $Y=20,629+0,536 X 1$.

Harga berpengaruh positif dan signifikan terhadap keputusan pembelian Tupperware pada Distributor Ishwarya Parama Ciputat Timur Tangerang Selatan. Hal ini dapat dilihat dari Nilai $t_{\text {hitung }}>t_{\text {tabel }}$ $(9,441>1,660)$ dan signifikan $t<0,05(0,000$ $<0,05)$ harga mempunyai korelasi positif dengan keputusan pembelian sebesar 0,832 . Harga mempunyai kontribusi (R2) sebesar $47,6 \%$ terhadap keputusan pembelian Tupperware pada Distributor Ishwarya Parama Ciputat Timur Tangerang Selatan. Model regresi sederhana yang diperoleh adalah $Y=21,149+0,832 X 2$.

Kualitas produk dan harga secara bersama-sama berpengaruh positif dan signifikan terhadap keputusan pembelian Tupperware pada Distributor Ishwarya

Parama Ciputat Timur Tangerang Selatan. Hal ini dapat dilihat dari Nilai Fhitung $>$ Ftabel $(60,796>2,70)$ dan signifikan $F<0,05(0,000<0,05)$. Kualitas produk dan harga secara bersama-sama mempunyai kontribusi (R2) sebesar 55,2\% terhadap keputusan pembelian Tupperware pada Distributor Ishwarya Parama Ciputat Timur Tangerang Selatan, selebihnya $44,8 \%$ dipengaruhi oleh variabel lain yang tidak diteliti, misalnya promosi, kualitas pelayanan, lokasi. Model regresi berganda yang diperoleh adalah $\mathrm{Y}=16,623$ $+0,308 X 1+0,503 X 2$.

\section{DAFTAR PUSTAKA}

Alifa, N, H., \& Lutfie, H. (2018). “Pengaruh Harga dan Kualitas Produk Terhadap Keputusan Pembelian Produk Kaos Kaki Pada PT Soka Cipta Niaga", Eproceeding of Appliced Science, 4(2), 388-395.

AM, E. N., Affandi, A., Udobong, A., \& Sarwani, S. (2020). Implementation of Human Resource Management in the
Adaptation Period for New Habits. International Journal of Educational Administration, Management, and Leadership, 19-26.

Arikunto, S. (2010). Produser Penelitian: Suatu Pendekatan Praktik. Jakarta : Rineka Cipta.

Assauri, S. (2015). Manajemen Pemasaran. Jakarta : Rajawali Pers.

Hermawati, R., Sugiyarti, L., Handayani, R., Sunarsi, D., Alfiah, S., \& Maddinsyah, A. (2020). The Effect of Trilogy Leadership Style and Organization Culture on School Performance: Evidence form Indonesian Senior High School. PalArch's Journal of Archaeology of Egypt/Egyptology, 17(6), 8512-8537.

Kasanti, N., Wijaya, A., \& Suandry. (2019). "Pengaruh Harga dan Kualitas Produk Terhadap Keputusan Pembelian Produk Safety Merek Progourd Pada PT AIM Safety Indonesia", AJIE- Asian Journal Of Innovation and Entrepreneurship, Universitas Prima Indonesia, 4(1), 4351.

Kotler, P., \& Gary A. (2016). Prinsip-prinsip Pemasaran. Edisi 13. Jiid 1. Jakarta: Erlangga.

Kotler, P., \& Kevin, L. K. (2016). Marketing Management. Edisi 15. Global Edition United Kingdom: Pcarson Education.

Lupiyoadi, R., \& Ikhsan, R. B. (2015). Pratikum Metode Riset Bisnis. Jakarta: Salemba Empat.

Maddinsyah, A., Hidayat, D., Juhaeri, J., Susanto, D., \& Sunarsi, D. (2020). Desain Formulasi Dan Implementasi Bisnis Strategik Dengan Pendekatan Business Model Canvas (BMC) Terintegrasi Kerangka Integrated Performance Management System (IPMS) Pada Koperasi Asperindo. Inovasi, 7(2), 67-76.

Mas'adi, M. Pengaruh Periklanan Terhadap Keputusan Pembelian Produk Ponds Pada Hypermart Cabang Bintaro. JgK (Jurnal Guru Kita), 4(3), 28-35.

Muhtarom, A., \& Syahrizal, T. M. (2018). "Pengaruh Kualitas Produk dan 
Harga Terhadap Keputusan Pembelian Rokok Surya (Studi Kasus pada Konsumen Rokok Surya di UNISLA)", Jurnal Penelitian Ekonomi dan Akuntansi, Universitas Islam Lamongan, 3(1), 615-621.

Nurjaya, N., Sunarsi, D., Effendy, A. A., Teriyan, A., \& Gunartin, G. (2021). Pengaruh Etos Kerja Dan Disiplin Kerja Terhadap Kinerja Pegawai Pada Dinas Kehutanan Dan Perkebunan Kota Bogor. JENIUS (Jurnal Ilmiah Manajemen Sumber Daya Manusia), 4(2), 172-184.

Paeno, P., Kasmad, K., Sunarsi, D., Maddinsyah, A., \& Supiyan, D. (2020). Pemanfaatan Sampah Plastik Untuk Kerajinan Rumah Tangga Taman Belajar Kreatif Mekar Sari. Baktimas: Jurnal Pengabdian pada Masyarakat, 2(1), 57-61

Prasada, D., Sunarsi, D., \& Teriyan, A. (2020). Pengaruh Etos Kerja Dan Kompensasi Terhadap Komitmen Organisasi Pada DHL Logistic Di Jakarta. JENIUS (Jurnal Ilmiah Manajemen Sumber Daya Manusia), $4(1), 51-60$.

Priyatno. D. (2014). SPSS 22 Pengolah Data Terpraktis. Yogyakarta : Andi Publisher.

Putranto, I. \& Kartoni (2020). "Pengaruh Kualitas Produk dan Harga Terhadap Keputusan Pembelian Tupperware (Studi Kasus Ibu Rumah Tangga di Perumahan Kunciran)", Jurnal Mandiri : Ilmu Pengatahuan, Seni dan Teknologi, Universitas Pamulang, 4(1), 94-104.

R.Terry. G., \& Leslie W. R. (2010). DasarDasar Manajemen. Jakarta:Bumi Aksara.

Sampurnaningsih, S. R., Andriani, J., Zainudin, Z. A. B. A., \& Sunarsi, D. (2020). The Analysis of Entrepreneurship Character and Entrepreneurship Intention among Students. PalArch's Journal of Archaeology of Egypt/Egyptology, 17(6), 8290-8303.
Sudaryono. (2016). Manajemen Pemasaran Teori dan Implementasi. Yogyakarta : Andi Publisher.

Sugiyono. (2014). Metode Penelitian Pendidikan Pendekatan Kuantitatif, Kualitatif, dan R\&D, Bandung : Alfabeta.

Sugiyono. (2017). Metode Penelitian Kuantitatif, Kualitatif, dan R\&D, Cetakan ke 25. Bandung: Alfabeta.

Sunarsi, D., Maddinsyah, A., Ahidin, U., Roswendi, A. S., \& Supriadi, D. (2020). Implementasi Hypnotherapy dalam Meningkatkan Motivasi. JPM (Jurnal Pemberdayaan Masyarakat), 5(2), 499

- 506 https://doi.org/10.21067/jpm.v5i2.4 186

Suryani, N. L., Sularmi, L., Eka, P. D., Sunarsi, D., \& Maddinsyah, A. (2020). The Analysis of Career Development and Placement of Employee Performance in Pt. Global Means of Transindo in Jakarta. Solid State Technology, 63(6), 1382-1389.

Swasta, B., \& Hani, H. (2010). Manajemen Pemasaran: Analisa dan Perilaku Konsumen. Yogyakarta : BPFE.

Tjiptono, F., \& Anastasia, D. (2016). Pemasaran, Esensi \& Aplikasi. Yogyakarta: Andi Publisher.

Tjiptono, F., \& Gregorius, C. (2017). Pemasaran Strategik. Edisi ke-3. Yogyakarta: Andi (Anggota IKAPI).

Tunis, J, A. \& Martina, S. (2016). “Pengaruh Kualitas Produk dan Harga Terhadap Keputusan Pembelian Di Thesecret Factory Outlet", Pariwisata, ejournal.bsi.ac.id : Pariwisata, 3(1), 6072. 